\title{
Photochromism of Dihydroindolizines Part XI: Synthesis of Novel Carbon-Rich Photochromic Dihydroindolizines-Based Potential Electronic Devices
}

\author{
Saleh Abdel-Mgeed Ahmed ${ }^{1,2}$ \\ ${ }^{1}$ Chemistry Department, Faculty of Science, Assiut University, 71516 Assiut, Egypt \\ ${ }^{2}$ Chemistry Department, Faculty of Science, Taibah University, Al-Madina Al-Munawara 30002, Saudi Arabia
}

Correspondence should be addressed to Saleh Abdel-Mgeed Ahmed, saleh_63@hotmail.com

Received 9 July 2008; Accepted 12 October 2008

Recommended by Cyril Parkanyi

Novel carbon-rich photochromic dihydroindolizine (DHI) derivatives substituted in the fluorene part (region A) in addition to the new spirocyclopropene 6 have been synthesized. The synthesis of dimethyl $2^{\prime}, 7^{\prime}$-diethynylspiro[cycloprop[2] ene-1,9' -fluorene]2,3-dicarboxylate precursor 6 was accomplished in five steps, starting with the literature known conversion of fluorene to 2,7dibromo-9H-fluoren-9-one in 56\% yield over three steps. The chemical structures of the new synthesized materials have been elucidated by both analytical and spectroscopic tools. Three alterative synthetic pathways for the synthesis of DHI 9 have been established.

Copyright (C) 2008 Saleh Abdel-Mgeed Ahmed. This is an open access article distributed under the Creative Commons Attribution License, which permits unrestricted use, distribution, and reproduction in any medium, provided the original work is properly cited.

\section{Introduction}

Molecules that respond to the application of external stimuli by undergoing reversible transformations between two distinct structures have the potential to significantly influence the development of numerous important materials science and structural biology technologies $[1,2]$. This potential is based on the fact that, because the molecules typically undergo dramatic changes in their electronic and topological characteristics, they can act as switching elements and other dynamic components in various optoelectronic devices and functional materials. Photons are particularly appealing stimuli because modern lasers can be used to achieve fast response times, to focus a fine-tuned stimulus on small localized domains without significant diffusion and to trigger photochemical events under conditions mild enough to pose minimal danger to sensitive biomaterials. Compounds that interconvert between different isomers having unique absorption spectra when stimulated with light are referred to as photochromic, and the process is called photochromism. In these systems, the changes in the electronic patterns responsible for the changes in color also result in variations in other practical physical properties such as luminescence [3], electronic conductance $[4,5]$, refractive index [6], optical rotation [7], and viscosity [8,9]. These materials, based on the 1,5-electrocyclization between two distinct isomeric states: ring-opening form (betaine-form) and ring-closed form (DHI-form), are promising candidates for optical storage media and electronic devices [10-29].

As a continuation of our research on photochromic dihydroindolizines (DHIs), this manuscript is devoted to the synthesis of carbon-rich fluorenyl-dihydroindolizines derivatives and represents the first step toward the application of photochromic dihydroindolizines in electronic devices. Different synthetic approaches will be described.

\section{Results and Discussion}

\subsection{Synthesis of Fluorenylacetylene Spirocyclopropene Precursor 6}

The synthesis of spirocyclopropene $\mathbf{6}$ was accomplished in five steps, starting with the previously known conversion of fluorene to 2,7-dibromo-9H-fluoren-9-one in 


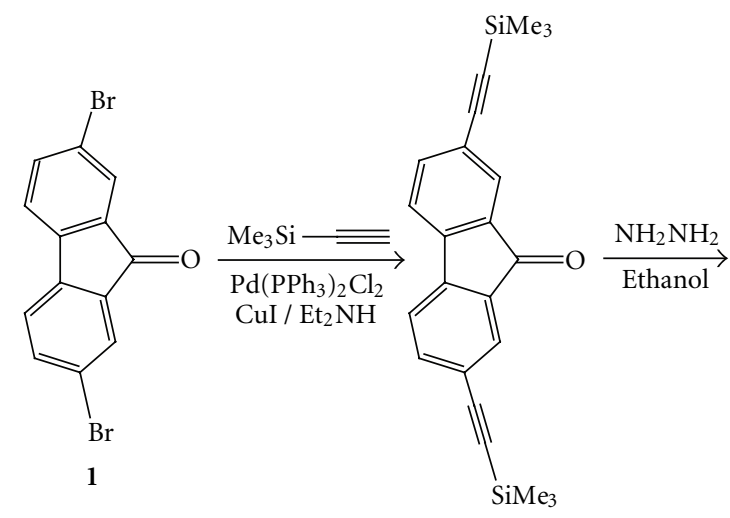

2<smiles>C#Cc1ccc2c(c1)C(=N)c1cc(C#C)ccc1-2</smiles><smiles>C#Cc1ccc2c(c1)C(=N)c1cc(C#CC)ccc1-2</smiles>

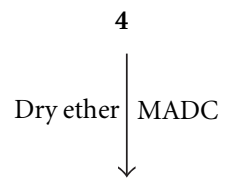<smiles>C#Cc1ccc2c(c1)C1(C(C(C)=O)=C1C(=O)OC)c1cc(C#C)ccc1-2</smiles><smiles>[Mg][Mg][Mg]</smiles><smiles>C#Cc1ccc2c(c1)C1(N=NC(C(=O)OC)=C1C(C)=O)c1cc(C#C)ccc1-2</smiles>

MADC: $\mathrm{H}_{3} \mathrm{COOCC}$

$\mathrm{C}-\mathrm{COOCH}_{3}$

Scheme 1: The synthesis of dimethyl 2',7'-diethynylspiro[cycloprop[2] ene-1,9'-fluorene]-2,3-dicarboxylate precursor 6.
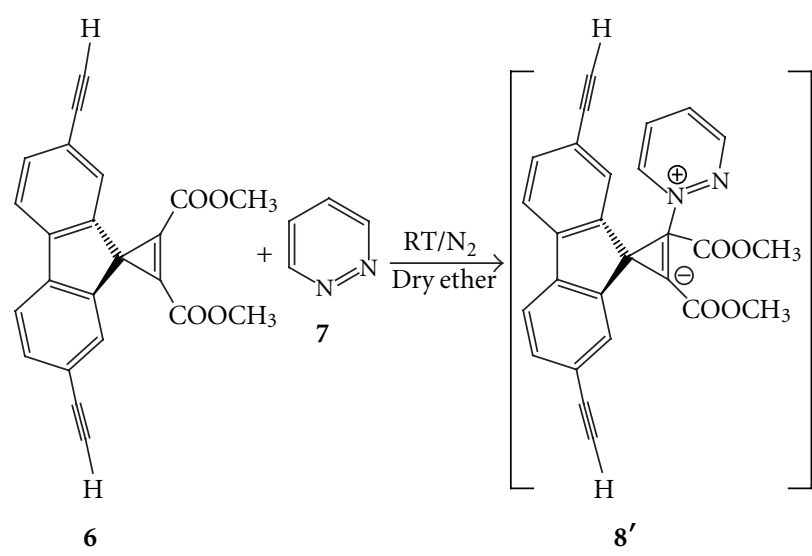

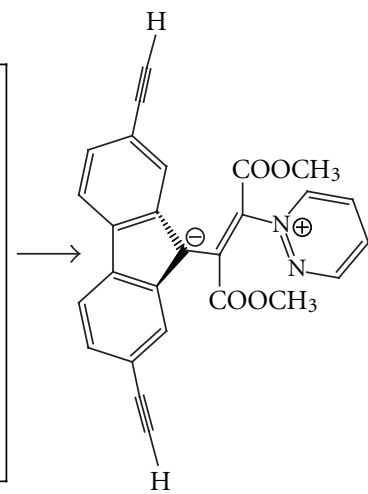

8 (betaine form)

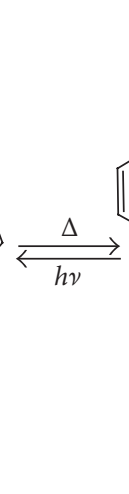<smiles>C#Cc1ccc2c(c1)C[C@]1(C(C(=O)OC)=C(C(=O)OC)N3N=CC=C[C@@H]31)c1cc(C#C)ccc1-2</smiles>

9 (DHI)

Scheme 2: Preparation outline of photochromic DHI 9 from spirocyclopropene 6.

$56 \%$ yield in over three steps [10-13] (see Scheme 1). The Sonogashira-coupling of 2,7-dibromo-9H-fluoren-9one with trimethylsilylacetylene (TMSA) in the presence of $\mathrm{Pd}(\mathrm{PPh})_{3} \mathrm{Cl}_{2} \quad(5 \mathrm{wt} \%) / \mathrm{CuI} / \mathrm{Et}_{2} \mathrm{NH}$ in $\mathrm{THF}$ at room temperature for 24 hours afforded the coupling product 2,7-bis((trimethylsilyl)ethynyl)-9H-fluoren-9-one $\mathbf{2}$ in good yield $(79 \%)$. Interestingly, condensation of compound 2 with hydrazine hydrate in boiling ethanol for 6 


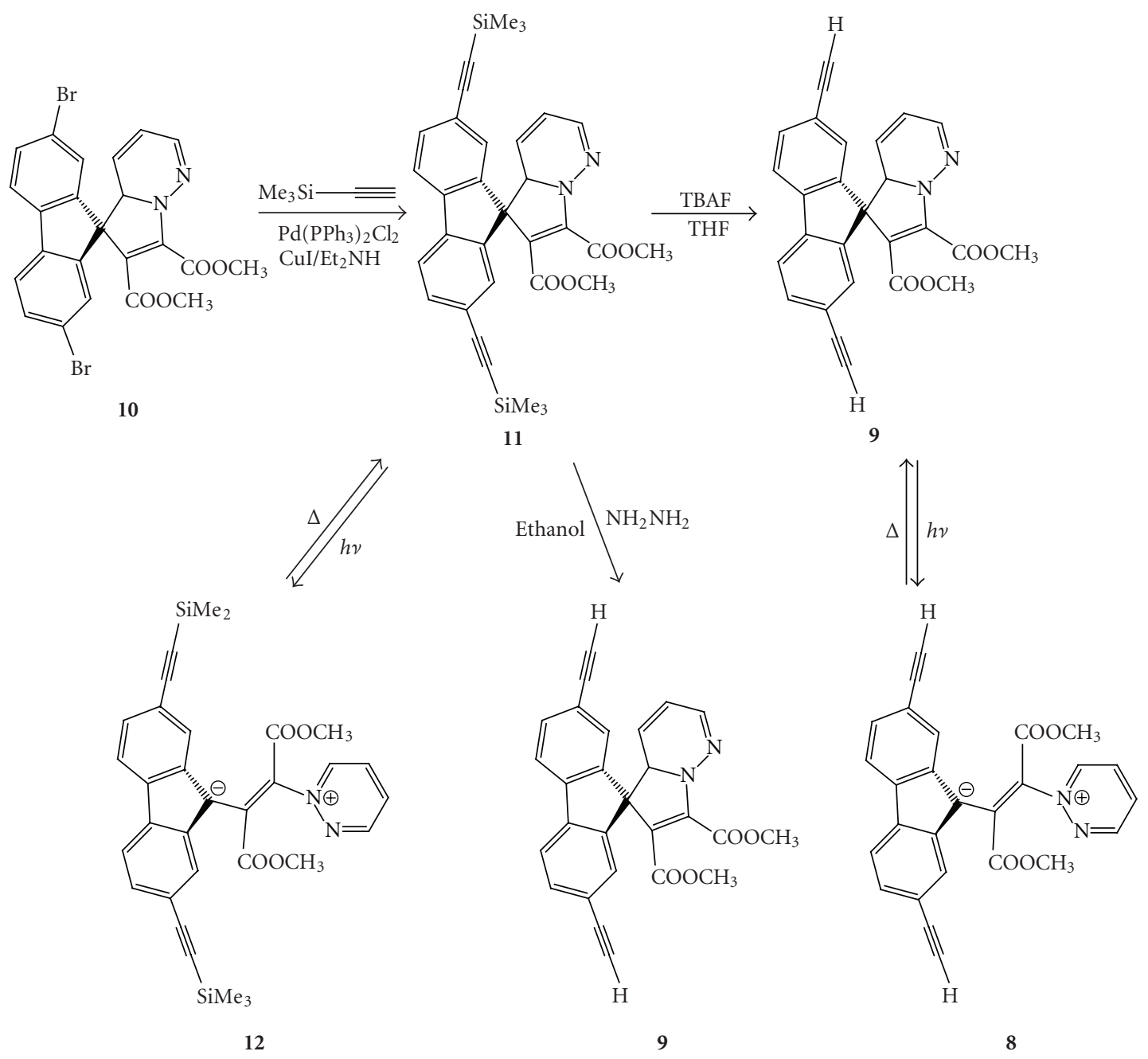

Scheme 3: Another reaction pathway for the synthesis of the target photochromic DHI 9.

hours leads not only to the formation of the condensation product (2,7-bis((trimethylsilyl)ethynyl)-9H-fluoren-9hydrazone but also to the occurrence of dimethyl silylation, and to the obtainment of (2,7-di(prop-1-ynyl)-9H-fluoren9 -ylidene)hydrazone 3 in $47 \%$ yield. The evidence for the formation of compound 3 was established by ${ }^{1} \mathrm{HNMR}$ which showed the complete disappearance of the trimethylsilyl protons which appear as singlet at $0.4 \mathrm{ppm}$ in compound 2 and the appearance of a singlet at $4.05 \mathrm{ppm}$ in compound 3 which is related to the acetylenic proton in addition to the presence of a broad singlet at $5.32 \mathrm{ppm}$ corresponding to the $\mathrm{NH}_{2}$ protons which disappeared upon treatment with deuterium oxide. Oxidation of the hydrazone 3 with manganese dioxide in dry ether at room temperature in the absence of light afforded the 9-diazo-2,7-di(prop-1-ynyl)$9 \mathrm{H}$-fluorene $\mathbf{4}$ in moderate yield (56\%). Addition of methyl acetylenedicarboxylate (MADC) to the 9-diazofluorene derivative $\mathbf{4}$ in dry ether in dark condition for 24 hours led to the formation of dimethyl 2,7-diethynylspiro[fluorene-9, $3^{\prime}$ pyrazole]- $4^{\prime}, 5^{\prime}$-dicarboxylate 5 pyrazole derivative 6 in 37\% yield.
Photolysis of the pyrazole derivative $\mathbf{5}$ with high pressure mercury lamp $(125 \mathrm{~W})$ in dry ether solution for two hours under nitrogen atmosphere gave the target dimethyl $2^{\prime}, 7^{\prime}$-diethynylspiro[cycloprop[2]ene-1,9'fluorene]-2,3-dicarboxylate 6 in low yield $(22 \%)$. The reaction was accompanied with the formation of some unidentified product which is expected to be related to some addition polymerization on the two acetylenic groups in the fluorene part (region A) which leads to the decreasing of the yield of the desired spirocyclopropene derivative $\mathbf{6}$. The chemical structure of the newly synthesized compounds 2-6 (see Scheme 1) was confirmed and established by both spectroscopic (NMR, IR, and mass spectrometry) and analytical tools (give satisfactory elemental analysis data). For example, the ${ }^{1} \mathrm{HNMR}\left(400 \mathrm{MHz}, \mathrm{CDCl}_{3}\right)$ of the spirocyclopropene precursor 6 showed the following signals: $\delta$ 7.82-7.86 (d, $J=1.76 \mathrm{~Hz}, 1 \mathrm{H}, \mathrm{CH}$-arom.), $7.63-7.67(\mathrm{~d}, J=1.32 \mathrm{~Hz}, 1 \mathrm{H}$, $\mathrm{CH}$-arom.), 7.52-7.57 (m, 4H, CH-arom.), 4.11 (s, $2 \mathrm{H}$, acetylenic protons in 2,7 position), $3.82\left(\mathrm{~s}, 6 \mathrm{H}, 2^{\prime}, 3^{\prime}-\mathrm{CH}_{3}\right)$ ppm. 


\subsection{Different Attempts for Synthesis of the Photochromic Dihydroindolizine 9}

Nucleophilic addition of pyridazine 7 to spirocyclopropene 6 using the cyclopropene route [10-29] (see Scheme 2) in dry ethereal solution at room temperature under dry nitrogen in the absence of light (TLC-controlled using $\mathrm{CH}_{2} \mathrm{Cl}_{2}$ as eluent) led to the formation of the photochromic dihydroindolizine (DHI) 9 in low yield (26\%). The reaction occurs through the electrophilic addition of the electrondeficient spirocyclopropenes $\mathbf{6}$ tothe nitrogen of the $\mathrm{N}$ heterocyclic pyridazine 7 which led to ring opening via a cyclopropyl-allyl conversion $\mathbf{8}^{\prime}$ to the colored betaines 8. A subsequent ring closure to DHI 9 results in a slow thermal 1,5-electrocyclization back reaction (see Scheme 2) which can be reversed upon exposure to light. Pure photochromic DHI 9 was obtained in all cases by two successive column chromatography operations on silica gel using dichloromethane as the eluent.

Another successful alternative method for the synthesis of the target photochromic DHI 9 was achieved through the following multistep synthesis (see Scheme 3). The Sonogashira coupling of dimethyl 2,7-dibromo- $4 \mathrm{a}^{\prime} \mathrm{H}-$ spiro [fluorene- $9,5^{\prime}$-pyrrolo [1,2-b] pyridazine] $-6^{\prime}, 7^{\prime}$ - dicarboxylate which was previously prepared by us [10-13] with trimethylsilylacetylene in presence of palladiumcatalyzed reaction $(5 \%)$ and $\mathrm{CuI} / \mathrm{Et}_{2} \mathrm{~N}$ in $\mathrm{T}=$ dry $\mathrm{THI}$ for 12 hours [29, 30] yielded the desired product dimethyl 2,7-bis((trimethylsilyl)ethynyl)-4a' H-spiro[fluorene-9,5'pyrrolo[1,2-b]pyridazine]- $6^{\prime}, 7^{\prime}$-dicarboxylate 11 in $34 \%$ yield after purification by flash chromatography on silica gel and $\mathrm{CH}_{2} \mathrm{Cl}_{2}$ as eluent. Treatment of DHI 11 with tetrabutyl ammonium fluoride (TBAF) in dry THF for 17 hours afforded the trimethylsilylated product 9 in $68 \%$ yield. A good proof for the trimethylsilylation that occurs during the condensation of compound 2 with hydrazine hydrate is that detrimethylsilylation occurs when DHI $\mathbf{1 1}$ was treated with hydrazine hydrate in ethanol under mild conditions and at low temperature $\left(0^{\circ} \mathrm{C}\right)$ for 2 hours in $43 \%$ yield. Thus, acetylenic DHI 9 could successfully prepared through three reactions' pathways as shown in Schemes 2 and 3. The three products obtained from the different pathways showed the same analytical and spectroscopic data as well as m.p and m.m.p.

\section{Conclusion}

We have successfully extended the photochromism of photochromic DHI through the coupling reactions in the fluorene part. New spirocyclopropene and photochromic dihydroindolizines (DHIs) substituted in the fluorene part (region A) with acetylenic bridge for future using in electronic devices have been furnished. Further modification of the chemical structure of DHI system and their photochromic properties as well as supporting onto the surface of metals such as gold, silicon, and titanium will be discussed in details in the forthcoming paper.

\section{Experimental}

Spirocyclopropene derivatives were obtained via photolysis of the corresponding pyrazoles prepared according to reported procedures [10-23]. Photolysis was carried out in the photochemical reactor of Schenck [31] made from Pyrex $(\lambda>290 \mathrm{~nm})$. The source of irradiation was a high-pressure mercury lamp Philips HPK $125 \mathrm{~W}$. Solutions to be photolyzed were flushed with dry nitrogen for 30 minutes before switching on the UV lamp. The progress of the reaction and the purity of the products isolated were monitored using TLC. Separation and purification of all synthesized photochromic materials were carried out using column chromatography ( $80 \mathrm{~cm}$ length $\times 2 \mathrm{~cm}$ diameter) on silica gel and $\mathrm{CH}_{2} \mathrm{Cl}_{2}$ as eluent. Melting points were determined on (Electrothermal Eng. Ltd., Essex, UK) melting point apparatus and are uncorrected. All NMR spectra were collected on a Brüker DRX-400 spectrometer $(400 \mathrm{MHz})$ in $\mathrm{CDCl}_{3}$ using TMS as the internal standard. Chemical shifts $(\delta)$ are reported in ppm. Experimental details, procedures, and full characterizations of the new synthesized compounds will be described elsewhere.

\section{Acknowledgments}

The author is highly indebted to Alexander von Humboldt Foundation $(\mathrm{AvH})$ for the financial support of this work. Also, the financial support from the Taibah University (Project no. 48/427) is gratefully acknowledged.

\section{References}

[1] M. Irie, in Molecular Switches, B. L. Feringa, Ed., pp. 37-60, Wiley-VCH, Weinheim, Germany, 2001.

[2] M. Irie, in Organic Photochromic and Thermochromic Compounds, J. C. Crano and R. J. Gugielmetti, Eds., vol. 1, pp. 207221, Plenum Press, New York, NY, USA, 1999.

[3] M. Irie, T. Fukaminato, T. Sasaki, N. Tamai, and T. Kawai, "A digital fluorescent molecular photoswitch,” Nature, vol. 420, no. 6917, pp. 759-760, 2002.

[4] T. Tsujioka, Y. Hamada, K. Shibata, A. Taniguchi, and T. Fuyuki, "Nondestructive readout of photochromic optical memory using photocurrent detection," Applied Physics Letters, vol. 78, no. 16, pp. 2282-2284, 2001.

[5] T. Kawai, T. Kunitake, and M. Irie, "Novel photochromic conducting polymer having diarylethene derivative in the main chain," Chemistry Letters, vol. 28, no. 9, pp. 905-906, 1999.

[6] C. Bertarelli, A. Bianco, F. D’Amore, M. C. Gallazzi, and G. Zerbi, "Effect of substitution on the change of refractive index in dithienylethenes: an ellipsometric study," Advanced Functional Materials, vol. 14, no. 4, pp. 357-363, 2004.

[7] R. A. van Delden, M. K. J. ter Wiel, and B. L. Feringa, "A chiroptical molecular switch with perfect stereocontrol," Chemical Communications, vol. 10, no. 2, pp. 200-201, 2004.

[8] M. Moniruzzaman, C. J. Sabey, and G. F. Fernando, "Synthesis of azobenzene-based polymers and the in-situ characterization of their photoviscosity effects," Macromolecules, vol. 37, no. 7, pp. 2572-2577, 2004. 
[9] L. N. Lucas, J. van Esch, R. M. Kellogg, and B. L. Feringa, "Photocontrolled self-assembly of molecular switches," Chemical Communications, no. 8, pp. 759-760, 2001.

[10] S. A.-M. Ahmed, T. Hartmann, V. Huch, H. Dürr, and A. A. Abdel-Wahab, "Synthesis of IR-sensitive photoswitchable molecules: photochromic 9'-styrylquinolinedihydroindolizines," Journal of Physical Organic Chemistry, vol. 13, no. 9, pp. 539-548, 2000.

[11] Y. Tan, S. A.-M. Ahmed, H. Dürr, V. Huch, and A. AbdelWahab, "First intramolecular trapping and structural proof of the key intermediate in the formation of indolizine photochromics," Chemical Communications, no. 14, pp. 12461247, 2001.

[12] S. A.-M. Ahmed, "Photochromic spirotetrahydroazafluorenes: part IV. First trapping of novel type of cis-fixed photochromes based on pyridazinopyrrolo[1,2-b]isoquinoline," Molecular Crystals and Liquid Crystals, vol. 430, pp. 295-300, 2005.

[13] S. A.-M. Ahmed and H. Dürr, "Photochromic spirotetrahydroazafluorenes: part V. Why photochromic molecules with rigid region B exhibiting extremely fast bleaching process?" Molecular Crystals and Liquid Crystals, vol. 431, pp. 275-280, 2005.

[14] S. A.-M. Ahmed, "Photochromism of dihydroindolizines. Part III [1]. Synthesis and photochromic behavior of novel photochromic dihydroindolizines incorporating a cholesteryl moiety," Monatshefte für Chemie, vol. 135, no. 9, pp. 11731188, 2004.

[15] S. A.-M. Ahmed, A.-M. Abdel-Wahab, and H. Dürr, "Steric substituent effects of new photochromic tetrahydroindolizines leading to tunable photophysical behavior of the colored betaines," Journal of Photochemistry and Photobiology A, vol. 154, no. 2-3, pp. 131-144, 2003.

[16] S. A.-M. Ahmed, "Photochromism of dihydroindolizines. Part II. Synthesis and photophysical properties of new photochromic IR-sensitive photoswitchable substituted fluorene-9' -styrylquinolinedihydroindolizines," Journal of Physical Organic Chemistry, vol. 15, no. 7, pp. 392-402, 2002.

[17] S. A.-M. Ahmed, "Photochromism of dihydroindolizines part VI: synthesis and photochromic behavior of a novel type of IR-absorbing photochromic compounds based on highly conjugated dihydroindolizines," Journal of Physical Organic Chemistry, vol. 19, no. 7, pp. 402-414, 2006.

[18] S. A.-M. Ahmed, "Photochromism of dihydroindolizines part VII: multiaddressable photophysical properties of new photochromic dihydroindolizines bearing substituted benzo[i]phenanthridine as a fluorescing moiety," Journal of Physical Organic Chemistry, vol. 20, no. 8, pp. 574-588, 2007.

[19] S. A.-M. Ahmed, "Photochromism of dihydroindolizines part VI: synthesis and photochromic behavior of a novel type of IR-absorbing photochromic compounds based on highly conjugated dihydroindolizines," Journal of Physical Organic Chemistry, vol. 19, no. 7, pp. 402-414, 2006.

[20] S. A.-M. Ahmed, T. Hartmann, and H. Dürr, "Photochromism of dihydroindolizines. Part VIII.First holographic image recording based on di- and tetrahydroindolizines photochromes," Journal of Photochemistry and Photobiology A, vol. 200, no. 1, pp. 50-56, 2008.

[21] S. A.-M. Ahmed and J.-L. Pozzo, "Photochromism of dihydroindolizines Part IX. First attempts towards efficient selfassembling organogelators based on photochromic dihydroindolizines and $N$-acyl-1, $\omega$-amino acid units," Journal of Photochemistry and Photobiology A, vol. 200, no. 1, pp. 57-67, 2008.
[22] H. Dürr, C. Schommer, and T. Münzmay, "Dihydropyrazolopyridine und Bis(dihydroindolizine) - neuartige monound difunktionelle photochrome Systeme," Angewandte Chemie, vol. 98, no. 6, pp. 565-567, 1986.

[23] H. Dürr, C. Schommer, and T. Münzmay, "Dihydropyrazolopyridine and bis(dihydroindolizine)-novel mono- and bifunctional photochromic systems," Angewandte Chemie International Edition in English, vol. 25, no. 6, pp. 572-574, 1986.

[24] R. Fromm, S. A.-M. Ahmed, T. Hartmann, V. Huch, A. A. Abdel-Wahab, and H. Dürr, "A new photochromic system based on a pyridazinopyrrolo[1,2-b]pyridazine with ultrafast thermal decoloration," European Journal of Organic Chemistry, vol. 2001, no. 21, pp. 4077-4080, 2001.

[25] S. A.-M. Ahmed, A. A. Abdel-Wahab, and H. Dürr, "Photochromic nitrogen-containing compounds," in CRC Handbook of Organic Photochemistry and Photobiology, W. M. Horspool and F. Lenci, Eds., chapter 96, pp. 1-25, CRC press, New York, NY, USA, 2nd edition, 2003.

[26] H. Dürr, "Perspectives in photochromism: a novel system based on the 1,5-electrocyclization of heteroanalogous pentadienyl anions," Angewandte Chemie International Edition in English, vol. 28, no. 4, pp. 413-431, 1989.

[27] S. A.-M. Ahmed, C. Weber, Z. A. Hozien, Kh. M. Hassan, A. A. Abdel-Wahab, and H. Dürr, unpublished results.

[28] S. A.-M. Ahmed, Ph. D. thesis, Saarland-Assiut Universities, 2000.

[29] S. Zarwell and K. Rück-Braun, "Synthesis of an azobenzenelinker-conjugate with tetrahedrical shape," Tetrahedron Letters, vol. 49, no. 25, pp. 4020-4025, 2008.

[30] H. Jian and J. M. Tour, "En route to surface-bound electric field-driven molecular motors," Journal of Organic Chemistry, vol. 68, no. 13, pp. 5091-5103, 2003.

[31] A. Schönberg, Präparative Organische Photochemie, chapter 1, Springer, Berlin, Germany, 1958. 


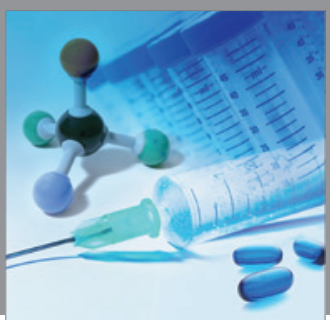

International Journal of

Medicinal Chemistry

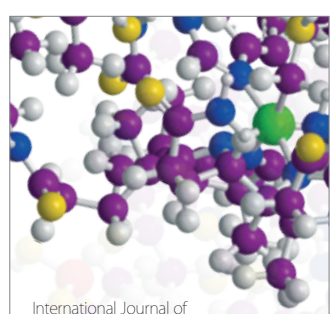

Carbohydrate Chemistry

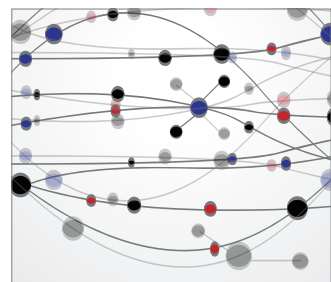

The Scientific World Journal
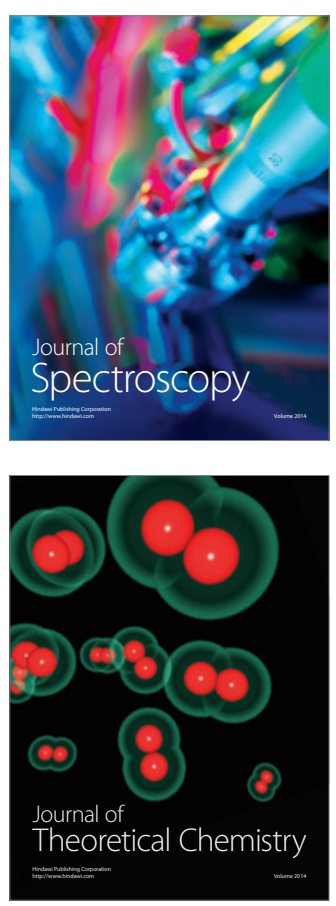
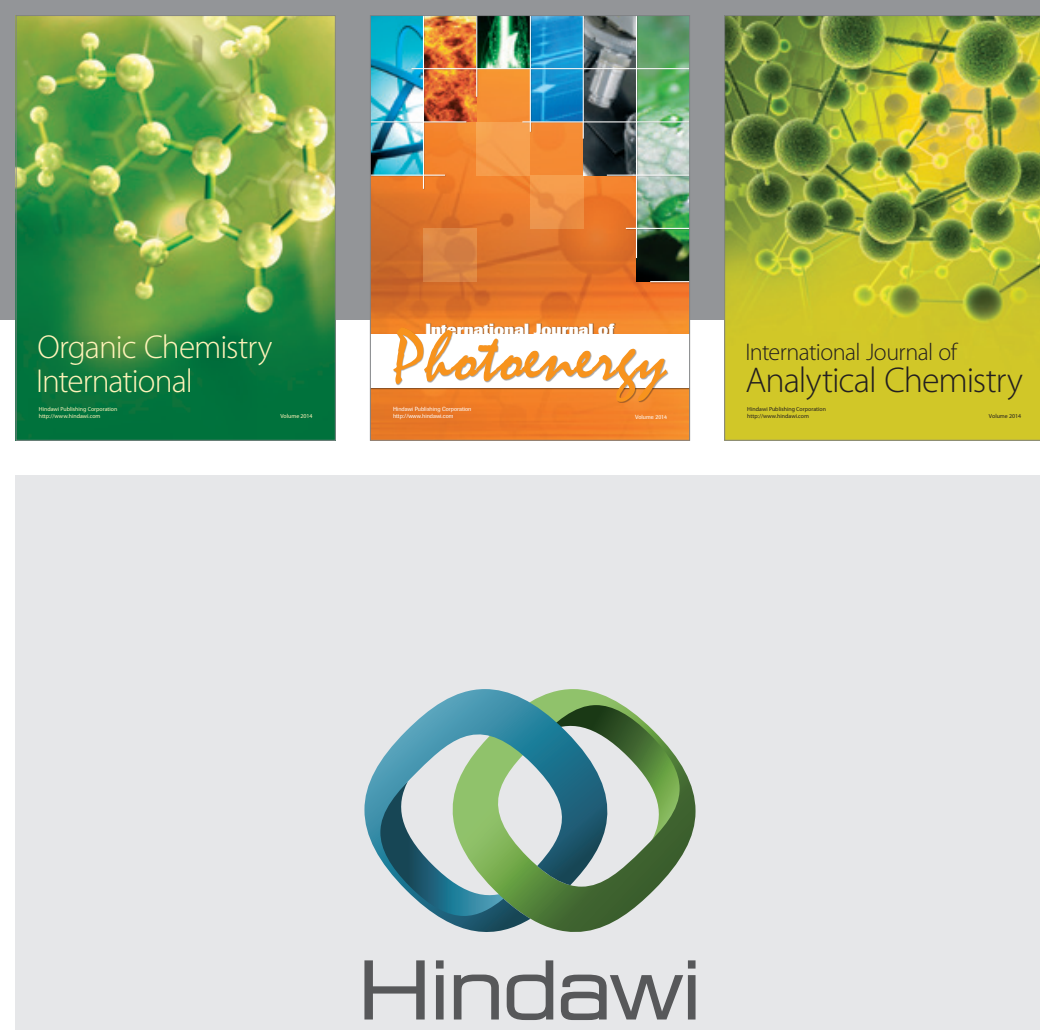

Submit your manuscripts at

http://www.hindawi.com
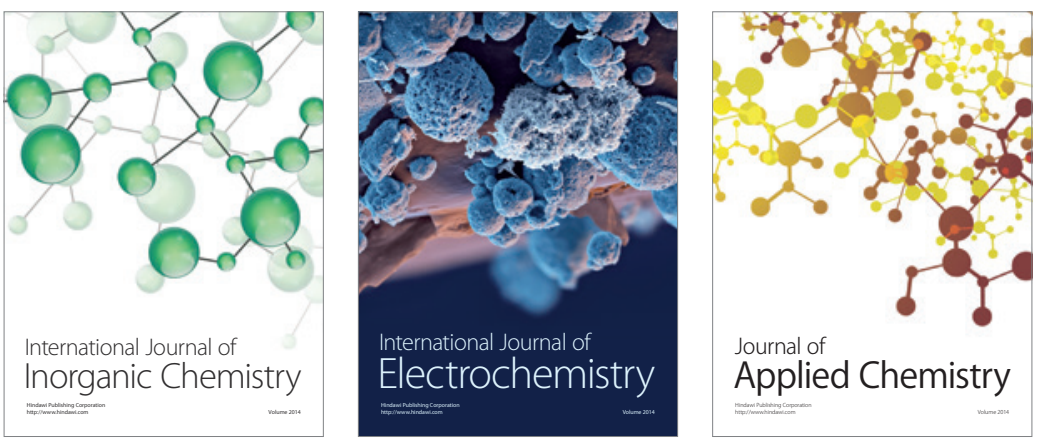

Journal of

Applied Chemistry
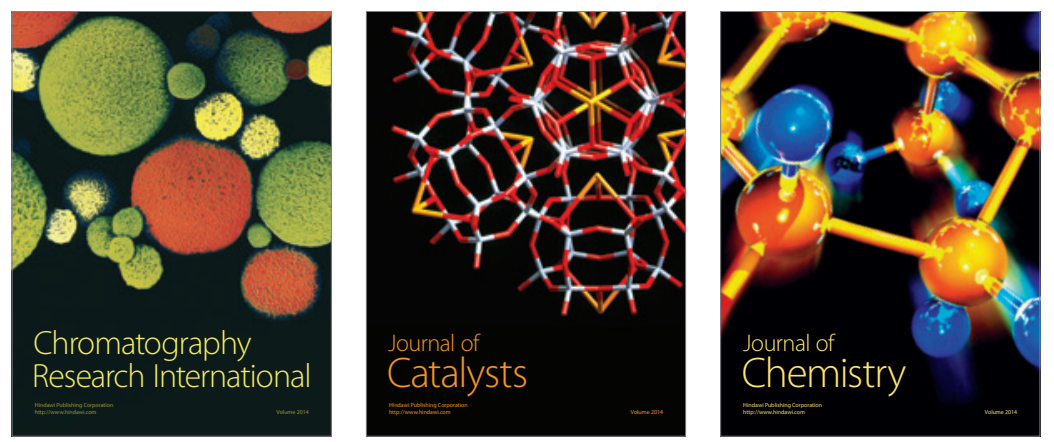
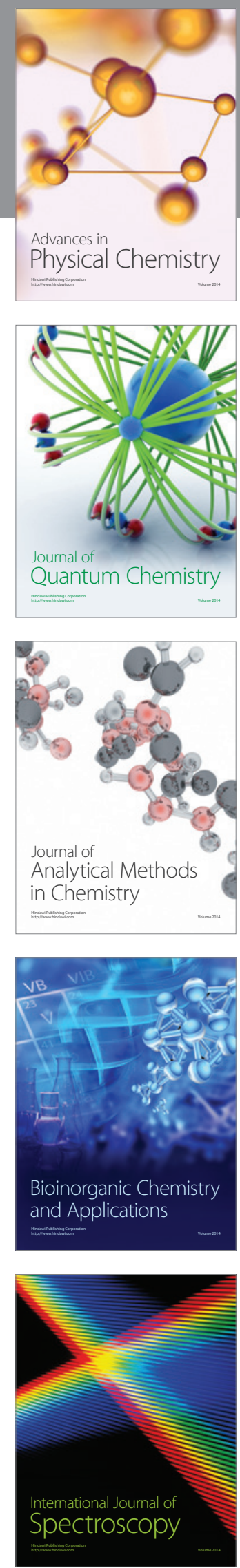